\title{
Silver-Enhanced Reduction of 2,3,5-Triphenyl-2H-tetrazolium by Semicarbazide for the Spectrophotometric Determination of Traces of Silver(I)
}

\author{
Padmarajaiah NagaraJa, ${ }^{* \dagger}$ Mattighatta S. Hemantha Kumar, ${ }^{* *}$ and Hemmige S. Yathirajan* \\ *Department of Studies in Chemistry, University of Mysore, Manasagangothri, Mysore-570 006, India \\ **Department of Studies in Environmental Science, University of Mysore, Manasagangotri, \\ Mysore-570 006, India
}

\begin{abstract}
A sensitive spectrophotometric method for the determination of silver is described. The reaction involves a silverenhanced reduction of 2,3,5-triphenyl- $2 \mathrm{H}$-tetrazolium chloride by semicarbazide hydrochloride to yield a pink-colored product with maximum absorption at $510 \mathrm{~nm}$. Beer's law is obeyed in the concentration range of $0.02-0.34 \mu \mathrm{g} \mathrm{cm}{ }^{-3} \mathrm{of}$ silver, and the molar absorptivity is $4.51 \times 10^{5} 1 \mathrm{~mol}^{-1} \mathrm{~cm}^{-1}$. The optical parameters, optimum reaction conditions and interference studies have been described. The method has been applied to the determination of silver in photographic film waste water and in synthetic samples.
\end{abstract}

(Received December 25, 2001; Accepted April 12, 2002)

\section{Introduction}

Many spectrophotometric methods have been reported for the determination of silver. ${ }^{1-3}$ Among the very recent methods, the spectrophotometric determination of silver with 5,10,15,20tetrakis-(4-bromophenyl)-21 $\mathrm{H}, 23 \mathrm{H}$-porphine ${ }^{4}$ and using 1,10phenanthroline and tetrabromophenolphthalein ethyl ester ${ }^{5}$ has been reported. 2,3,5-Triphenyl- $2 \mathrm{H}$-tetrazolium chloride (TTC) ${ }^{6}$ is used as a sensitive reagent for reducing sugars, used in histochemical studies and in the determination of antibiotics. TTC is also used to oxidize aldoses and ketoses. The chlorophyll-photosensitized reduction of TTC by hydrazine hydrate has been reported. ${ }^{7}$ The colorimetric determinations of iron(III), chromium(VI), thallium(III), aromatic and $\alpha, \beta$ unsaturated aldehydes by using an equimolar mixture of isonicotinic acid hydrazide and TTC have been reported. ${ }^{8} \mathrm{~A}$ colorimetric micro determination of 2-deoxy-D-glucose with TTC has been described. ${ }^{9}$ Ramesh et al. ${ }^{10}$ have recently reported the extractive separation of selenium and tellurium using TTC. An excellent review on the tetrazolium salts and formazans has been reported. ${ }^{11}$

In the present investigations, a highly sensitive spectrophotometric method for the determination of silver, that is, a new route involving the reduction of TTC by semicarbazide hydrochloride ( $\mathrm{SCH}$ ) using silver(I) in the presence of sodium hydroxide and nitric acid to produce a pinkcolored product, is described. Interference studies involving various diverse species have been made. The results of applying the present method for the determination of silver in the photographic film waste water, and also in synthetic samples, compare favorably with the reported method. ${ }^{12}$

† To whom correspondence should be addressed.

E-mail: nagarajap@mailcity.com

\section{Experimental}

\section{Instrument}

A JASCO Model UVIDEC-610 spectrophotometer with 1.0 $\mathrm{cm}$ matched cells was used for electronic spectral measurements.

\section{Reagents}

2,3,5-Triphenyltetrazolium chloride (TTC), semicarbazide hydrochloride $(\mathrm{SCH})$ and silver nitrate were obtained from Sigma (St. Louis, USA). Sodium hydroxide pellets (BDH grade) and nitric acid (AR grade) were used. All of the other reagents were of analytical grade, and deionized water was used throughout the experiment.

\section{Solutions}

A $0.1575 \mathrm{~g}$ portion of dried silver nitrate was dissolved in water containing $1 \mathrm{~cm}^{3}$ of concentrated $\mathrm{HNO}_{3}$; the solution was made up to the mark with water in a $100 \mathrm{~cm}^{3}$ standard flask and stored in the dark. Solutions of lower concentrations were prepared by appropriate dilution of the stock solution. A $0.1 \%$ solution of TTC in water was used. Freshly prepared solutions were always used, and the solution of TTC was stored in the dark. A $0.5 \%$ solution of $\mathrm{SCH}$ in water was prepared, and a solution of $5 \mathrm{~mol} \mathrm{dm}^{-3} \mathrm{NaOH}$ was prepared by dissolving $\mathrm{NaOH}$ pellets in 11 of water; $500 \mathrm{~cm}^{3}$ of concentrated nitric acid was diluted to 11 with water to give a final concentration of 8 $\mathrm{mol} \mathrm{dm} \mathrm{d}^{-3}$.

\section{Recommended procedure}

An aliquot of a standard solution containing $0.5-8.5 \mu \mathrm{g}$ of silver(I) was transferred to a $25 \mathrm{~cm}^{3}$ calibrated flask. Then, 0.5 $\mathrm{cm}^{3}$ of a $0.1 \%$ TTC solution was added, followed by the addition of $1 \mathrm{~cm}^{3}$ of a $0.5 \% \mathrm{SCH}$ solution with swirling. Then, $3 \mathrm{~cm}^{3}$ of a $5 \mathrm{~mol} \mathrm{dm}{ }^{-3} \mathrm{NaOH}$ solution was added followed by 


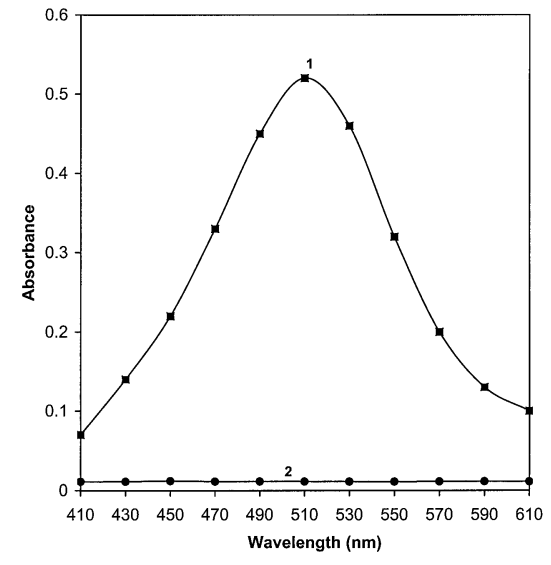

Fig. 1 Absorption spectra of the pink product (1) and the reagent blank (2). The final concentration of silver: $0.16 \mu \mathrm{g} \mathrm{cm}^{-3}$.

Table 1 Optical characteristics and precision data

\begin{tabular}{lc}
\hline Optical characteristics and precision & Parameter \\
\hline Color & Pink \\
$\lambda_{\max }(\mathrm{nm})$ & 510 \\
Stability (min) & 30 \\
Beer's law range $\left(\mu \mathrm{g} \mathrm{cm}^{-3}\right)$ & $0.02-0.34$ \\
Molar absorptivity $\left(\mathrm{mol}^{-1} \mathrm{~cm}^{-1}\right)$ & $4.51 \times 10^{5}$ \\
Sandells' sensitivity $\left(\mu \mathrm{g} \mathrm{cm}^{-2}\right)$ & 0.00024 \\
Optimum photometric range $\left(\mu \mathrm{g} \mathrm{cm}^{-3}\right)$ & $0.04-0.30$ \\
Detection limit $\left(\mu \mathrm{g} \mathrm{cm}^{-3}\right)$ & 0.008 \\
Regression equation $(Y)^{\mathrm{a}}$ & \\
Slope $(b)$ & 3.3204 \\
Intercept $(a)$ & -0.0108 \\
Correlation coefficient $(r)$ & 0.994 \\
Relative standard deviation & \\
Range of error & 0.2227 \\
\hline
\end{tabular}

a. $Y=b x+a$, where $x$ is the concentration of silver in $\mu \mathrm{g} \mathrm{cm}^{-3}$. b. Five replicates.

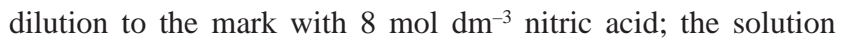
was then mixed well. The absorbance of the resulting pink solution was measured at $510 \mathrm{~nm}$ within 30 min against a freshly prepared reagent blank (without silver) prepared in the same manner.

\section{Determination of silver in photographic film waste water}

After photographic film washings were collected from local studios of Mysore, $1 \mathrm{~cm}^{3}$ of each solution was treated with one or two drops of concentrated nitric acid and diluted. The solution was filtered and made up to $25 \mathrm{~cm}^{3}$. The solution was further diluted to obtain lower concentrations. A known aliquot of this solution was pipetted into a $25 \mathrm{~cm}^{3}$ calibrated flask and continued according to the recommended procedure, as mentioned above.

\section{Determination of silver in synthetic samples}

The recommended procedure was also followed for synthetic samples, by taking known amounts of a silver nitrate solution. To determine the precision and accuracy of the method, recovery experiments were performed using the method of additions, and analyzed within the Beer's law limits.

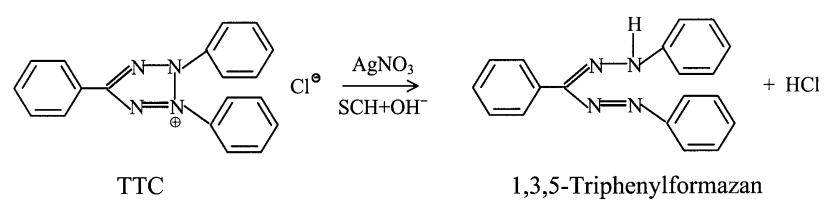

Scheme 1

\section{Results and Discussion}

Spectral characteristics of the colored product

A pink-colored product with maximum absorption at $510 \mathrm{~nm}$ was formed when TTC was reduced by SCH using silver nitrate. The absorption spectra of the reduced product as well as the reagent blank are shown in Fig. 1. The optical characteristics and the precision data are given in Table 1.

Optimization of reaction conditions

A $0.1 \%$ solution of TTC in the range of $0.5-2.0 \mathrm{~cm}^{3}$, a $0.5 \%$ solution of SCH in the range of $0.5-2.0 \mathrm{~cm}^{3}, 2.0-5.0 \mathrm{~cm}^{3}$ of a $5 \mathrm{~mol} \mathrm{dm} \mathrm{dm}^{-3} \mathrm{NaOH}$ solution and $7-9 \mathrm{~mol} \mathrm{dm}^{-3}$ nitric acid were necessary to develop the maximum color intensity. For excellent results, $1.0 \mathrm{~cm}^{3}$ of TTC, $1.0 \mathrm{~cm}^{3}$ of $\mathrm{SCH}, 3.0 \mathrm{~cm}^{3}$ of $\mathrm{NaOH}$ and $8 \mathrm{~mol} \mathrm{dm}^{-3}$ nitric acid were required. The maximum absorbance readings were obtained in the above ranges. Above or below these ranges, a decrease in the absorbance readings was noted, and the pink product was not stable.

\section{Stability of the colored product}

The instantaneous formation of the pink-colored product was stable for up to $30 \mathrm{~min}$ at room temperature $\left(27 \pm 2^{\circ} \mathrm{C}\right)$. After this time interval, the absorbance readings steadily decreased. Also, the absorbance readings remained constant in the temperature range of $20-60^{\circ} \mathrm{C}$. At temperatures above $60^{\circ} \mathrm{C}$, the absorbance values decreased, indicating dissociation of the product. However, a time of $30 \mathrm{~min}$ was sufficient to complete the analysis.

\section{Reaction mechanism}

The reaction involves the reduction of TTC by $\mathrm{SCH}$ using silver(I). Under the present conditions, TTC is reduced to 1,3,5triphenyltetrazolium formazan. The reaction mechanism is shown in Scheme 1. Without the addition of silver(I) ions, no color formation is noticed. With silver(I) ions and a $\mathrm{NaOH}$ solution, a purple precipitate of formazan is formed, which becomes clear pink upon the addition of nitric acid. Here, silver(I) ions enhance the reduction reaction. The plausible mechanism would be the reaction of two molecules of $\mathrm{Ag}(\mathrm{I})$ with three molecules of semicarbazide in an alkaline medium, leading to the oxidation of semicarbazide, liberating sixteen nascent hydrogen (eight nascent hydrogen per molecule of $\mathrm{Ag}(\mathrm{I})$ ), which in turn reduces four molecules of tetrazolium to four molecules of formazan, per molecule of silver(I). This means that four molecules of formazan are formed per molecule of $\operatorname{Ag}(\mathrm{I})$. Other acids and solvents were tried to increase the stability of the product, but were unsuccessful.

\section{Interference studies}

The effects of foreign ions and other substances were studied by taking $0.16 \mu \mathrm{g} \mathrm{cm}^{-3}$ of silver(I). An ion was considered to interfere if the obtained absorbance differed by more than $\pm 2 \%$ of the absorbance value from that of silver alone. The main interfering species were $\mathrm{NO}_{2}^{-}, \mathrm{Hg}^{2+}, \mathrm{Pb}^{2+}, \mathrm{Mn}^{2+}, \mathrm{Fe}^{2+}, \mathrm{Cu}^{2+}$, 
Table 2 Effect of diverse species on the determination of 0.16 $\mu \mathrm{g} \mathrm{cm}{ }^{-3}$ silver

\begin{tabular}{lc}
\hline Species & Tolerance limit $/ \mathrm{Mg} \mathrm{cm}^{-3}$ \\
\hline $\mathrm{EDTA}$, formaldehyde, sulfamic acid & 2000 \\
$\mathrm{NO}_{2}{ }^{-}, \mathrm{K}^{+}, \mathrm{CO}_{3}^{2-}, \mathrm{Zn}^{2+}, \mathrm{Na}^{+}, \mathrm{Ca}^{2+}, \mathrm{CH}_{3} \mathrm{COO}^{-}$ & 500 \\
$\mathrm{Tartarate}^{-} \mathrm{F}^{-}, \mathrm{SO}_{4}^{2-}, \mathrm{Mg}^{2+}, \mathrm{Fe}^{3+}, \mathrm{Al}^{3+}, \mathrm{Se}^{4+}$ & 300 \\
$\mathrm{SO}_{3}{ }^{2-}, \mathrm{CN}^{-}, \mathrm{b} \mathrm{Ni}^{2+}, \mathrm{Cl}^{-}, \mathrm{V}^{5+}, \mathrm{Cd}^{2+}$ & 100 \\
$\mathrm{Cu}^{2+}, \mathrm{Fe}^{2+}, \mathrm{Pb}^{2+}, \mathrm{Mn}^{2+}$ & $50^{c}$ \\
$\mathrm{~S}_{2} \mathrm{O}_{3}{ }^{2-}$ & 20 \\
\hline
\end{tabular}

a. Can be masked up to $500 \mu \mathrm{g} \mathrm{cm}^{-3}$ by the addition of $1 \mathrm{~cm}^{3}$ of $1 \%$ sulfamic acid solution.

b. Can be masked up to $100 \mu \mathrm{g} \mathrm{cm}^{-3}$ by the addition of $1 \mathrm{~cm}^{3}$ of $40 \%$ formaldehyde solution.

c. Can be masked up to $50 \mu \mathrm{g} \mathrm{cm}^{-3}$ by the addition of $1 \mathrm{~cm}^{3}$ of $1 \%$ EDTA solution.

$\mathrm{SCN}^{-}$and $\mathrm{CN}^{-}$. $\mathrm{Hg}^{2+}$ and $\mathrm{SCN}^{-}$could not be masked using any masking agents, whereas the other ions could be masked. The tolerance limits and other details are given in Table 2.

\section{Precision and accuracy}

The precision of the proposed method was ascertained from the absorbance values of the actual determinations of five replicates of fixed amounts of the silver sample. The percentage relative standard deviation was calculated by the proposed method. To determine the accuracy of the proposed method, different amounts of samples containing silver were taken within the Beer's law limits and analyzed by the recommended method. The results are given in Table 1.

\section{Application of the recommended method}

The proposed method has been applied to the determination of silver(I) in a photographic film waste water and also in synthetic samples. The results of analysis by the present method and the reported method ${ }^{12}$ agree favorably. The results are given in Table 3.

\section{Conclusion}

The proposed method for the determination of silver(I) is much simpler, and no critical conditions are necessary. The calibration curve can be precisely reproduced; extraction or heating is not necessary. The method has the advantages of being rapid, reproducible, selective and more sensitive than many other reported methods.
Table 3 Determination of silver in photographic film waste water and synthetic samples

\begin{tabular}{|c|c|c|c|c|c|}
\hline \multirow[b]{2}{*}{ Sample } & \multirow{2}{*}{$\begin{array}{l}\text { Silver } \\
\text { added/ } \\
\mu \mathrm{g} \mathrm{cm}^{-3}\end{array}$} & \multicolumn{2}{|c|}{ Proposed method } & \multicolumn{2}{|c|}{ Reported method $^{12}$} \\
\hline & & $\begin{array}{l}\text { Silver } \\
\text { found/ } \\
\mu \mathrm{g} \mathrm{cm}^{-3}\end{array}$ & $\begin{array}{c}\text { Mean } \\
\text { recovery, } \\
\%\end{array}$ & $\begin{array}{l}\text { Silver } \\
\text { found/ } \\
\mu \mathrm{g} \mathrm{cm}^{-3}\end{array}$ & $\begin{array}{c}\text { Mean } \\
\text { recovery, } \\
\%\end{array}$ \\
\hline \multirow{4}{*}{$\begin{array}{l}\text { Photographic } \\
\text { film waste } \\
\text { water }^{\mathrm{a}}\end{array}$} & - & 3.068 & - & 3.076 & - \\
\hline & - & 3.412 & - & 3.42 & - \\
\hline & - & 3.64 & - & 3.60 & - \\
\hline & - & 4.80 & - & 4.82 & - \\
\hline \multirow{5}{*}{$\begin{array}{l}\text { Synthetic } \\
\text { sample }\end{array}$} & 0.02 & 0.0199 & 99.5 & 0.0196 & 98.0 \\
\hline & 0.04 & 0.041 & 102.5 & 0.04 & 100.0 \\
\hline & 0.12 & 0.1198 & 99.83 & 0.1195 & 99.58 \\
\hline & 0.14 & 0.14 & 100.0 & 0.14 & 100.0 \\
\hline & 0.20 & 0.196 & 98.0 & 0.198 & 99.0 \\
\hline
\end{tabular}

a. Black \& white film washings collected around Mysore city (India).

\section{Acknowledgements}

One of the authors (M. S. H.) thanks Mysore University for the laboratory facilities.

\section{References}

1. S. C. Hung, C. L. Qu, and S. S. Wu, Talanta, 1982, 29, 85.

2. W. F. Sheng and Y. Fang, Talanta, 1983, 30, 190.

3. F. M. El-Zawawy, M. F. El-Shahat, A. A. Mohamed, and M. T. M. Zaki, Analyst, 1995, 120, 549.

4. Y. H. Zhang, Y. P. Liu, and Q. D. Ni, Fenxi Ceshi Xuebao, 1997, 16, 64.

5. T. Koh and T. Sugimoto, Anal. Chim. Acta, 1996, 333, 167.

6. "Merck Index", XII ed., 1996, 1660.

7. E. Fujimori, J. Am. Chem. Soc., 1955, 77, 6495.

8. M. H. Hashmi, A. Rashid, H. Ahmad, A. A. Ayaz, and F. Azam, Anal. Chem., 1965, 37, 1027.

9. J. Liu and X. Zhao, Fenxi Huaxue, 1983, 11, 196.

10. A. Ramesh and M. S. Subramanian, Bull. Chem. Soc. Jpn., 1998, $71,1025$.

11. F. P. Altman, Prog. Histochem. Cytochem., 1976, 9, 51.

12. T. Venkateshwarulu, T. Raman, and B. R. Reddy, Indian J. Chem., 1990, 29A, 930. 